\title{
UMA DISCUSSÃO META-ANALÍTICA DO DESEMPENHO EM MATEMÁTICA PARA O ENSINO MÉDIO BASEADO NOS RESULTADOS ATUAIS DO SARESP
}

\author{
Camila Fernanda BASSETTO ${ }^{1}$ \\ Sebastião de Souza LEMES ${ }^{2}$
}

RESUMO: O objetivo deste trabalho é realizar uma meta-análise dos resultados atuais do SARESP, considerando a proficiência em matemática de alunos do $3^{\circ}$ ano do Ensino Médio da rede pública estadual. Essa meta-análise permitiu identificar descompassos no conjunto do sistema educacional como um todo nos diversos seguimentos envolvidos, direta ou indiretamente, que contribuem para o processo de ensino-aprendizagem do indivíduo. Comparando os resultados atuais do SARESP, foi possível perceber a grande deficiência apresentada pelos alunos da $3^{\mathrm{a}}$ série do Ensino Médio em resolver problemas matemáticos envolvendo conceitos simples e do cotidiano, classificando-os em níveis abaixo do adequado, quando comparado com os níveis de desempenho esperados para à série em que se encontram. Diante deste fato, o qual não deixa de ser inaceitável, conclui-se que há uma urgente necessidade de buscar explicações e formas de superação para essa situação. Caso contrário, o nível educacional brasileiro permanecerá "abaixo do básico".

PALAVRAS-CHAVE: SARESP. Ensino médio. Proficiência em matemática. Metaanálise.

\section{Introdução}

A avaliação das capacidades cognitivas faz-se presente em diversas etapas da vida do indivíduo durante o processo educacional, com o intuito de promover melhorias na qualidade do ensino. É importante para avaliar os sistemas de ensino paulistas e nortear políticas públicas inteiramente voltadas à área educacional do Estado. Para Soares e Mendonça (2003, p.421), “Os sistemas de avaliação desenvolvidos na última década mantêm um mesmo objetivo prioritário: encontrar mecanismos para melhorar a qualidade do ensino oferecido à sociedade de forma eficaz e eficiente."

Intensificada no início da década de 90, a avaliação dos sistemas educacionais tornou-se, a partir daí um ponto relevante nas propostas de politicas públicas ligadas à

\footnotetext{
${ }^{1}$ UNESP - Universidade Estadual Paulista. Faculdade de Ciências e Letras - Departamento de Ciências da Educação. Araraquara - SP - Brasil. 14800-901 - camila@ fclar.unesp.br

2 UNESP - Universidade Estadual Paulista. Faculdade de Ciências e Letras - Programa de PósGraduação em Educação e do Departamento de Ciências da Educação. Araraquara - SP - Brasil. 14800901 - ss.lemes2@gmail.com
} 
educação. Está relacionada com a necessidade de uma melhor gestão dos recursos disponíveis, direcionando, de forma adequada, os investimentos na escola pública, e também com a necessidade de diagnosticar o ensino público objetivando efetivas melhorias ${ }^{3}$. Barbosa e Fernandes (2000) afirmam em seu estudo que a avaliação profunda e estruturada pode contribuir com o sistema promovendo correções e melhorias. De acordo com Lemes (2010, p.65), por avaliação “[...] entende-se a intenção de revelar e valorar a realidade do objeto avaliado, fundamentado em sua construção epistemológica."

Embora sob diferentes definições encontradas na literatura, a avaliação educacional tem o seu papel voltado, principalmente, a comprovar o rendimento escolar do aluno durante o seu percurso educacional, além de atuar estrategicamente em processos de reformas educacionais. Nesse sentido e contexto, é necessário que a avaliação rompa com a concepção de valoração de resultados e assuma o papel de instrumento de regulação - na dimensão pedagógica - no processo educativo escolar.

Na década de 90 no Brasil, a avaliação educacional começa a ter um papel de destaque nas políticas públicas, na busca por melhorias dos sistemas de avaliação implantados, e também visando responder e justificar o financiamento das políticas educacionais (BRASIL, 2011). Nos últimos anos, é perceptível o avanço obtido na área educacional considerando os recursos metodológicos disponíveis e os atuais critérios de avaliação, dentre os quais estão o Sistema Nacional de Avaliação da Educação Básica (SAEB), o Sistema de Avaliação do Rendimento Escolar do Estado de São Paulo (SARESP), o Exame Nacional do Ensino Médio (ENEM), o Exame Nacional para o Ensino e outros.

Os sistemas de avaliação citados, fundamentalmente com base na TRI - Teoria da Resposta ao Item (ANDRADE; KLEIN, 1999; ANDRADE; TAVARES; VALLE, 2000) - têm revelado um quadro crítico para a educação formal em relação ao desempenho e rendimento escolar do indivíduo. Para obter melhorias na qualidade do ensino e alcançar um sistema educacional eficaz, no qual o aluno aprenda, seja aprovado e conclua a educação básica dotado de competências para que seja capaz de armazenar, transformar e aplicar o conhecimento, é necessário que os responsáveis envolvidos nos processos de avaliação educacional entendam, decodifiquem e interpretem, à luz da realidade, os resultados dessas avaliações, explicitando a

\footnotetext{
${ }^{3}$ Até para conhecer os limites e as possibilidades estruturais de melhorias no sistema educacional público
} (BIZELLI, 2013). 
verdadeira deficiência evidenciada pelo aluno na avaliação de suas capacidades cognitivas.

Buscando contribuir com questões referentes à compreensão desse quadro nos sistemas de avaliação educacionais, o presente estudo tem por objetivo utilizar-se de uma meta-análise ${ }^{4}$ dos resultados atuais apresentados pelo SARESP relativo ao desempenho em matemática dos alunos da $3^{\text {a }}$ série do Ensino Médio nas escolas da rede pública. Esse procedimento possibilita a realização de análise e interpretação das proficiências $^{5}$ de forma compreensiva e realista.

Este artigo está organizado em seções, incluindo esta introdução e justificativa. Na seção 2 apresenta-se o Sistema de Avaliação de Rendimento Escolar do Estado de São Paulo, destacando suas principais características. Na seção 3 os resultados obtidos nas últimas edições do SARESP são apresentados e discutidos. Por fim, na seção 4 é apresentada a conclusão deste trabalho.

\section{O Sistema de Avaliação de Rendimento Escolar do Estado de São Paulo - SARESP}

O SARESP surge com a finalidade de atender melhor as avaliações que, até então, são de caráter mais pontual. Vem de um Programa de Avaliação Educacional da Rede Estadual do início da década de 1990, que visava verificar a ocorrência, ou não, de melhorias no desempenho dos alunos a partir de uma nova proposta pedagógica e metodológica para a escola.

Este Programa foi posteriormente estendido, por amostragem, às demais escolas estaduais como Sistema de Avaliação de Rendimento Escolar do Estado de São Paulo SARESP, implantado para avaliar o desempenho escolar dos alunos em diferentes séries do Ensino Fundamental e Médio, além de identificar os fatores internos e externos à escola que influenciam e interferem no rendimento e na aprendizagem na Educação Básica. São exigidas competências e habilidades previstas pelas Matrizes de Referência da Avaliação do currículo do Estado de São Paulo observando-se referenciais compatíveis com as exigências feitas pelo Sistema Nacional de Avaliação da Educação Básica, as quais se espera serem plenamente desenvolvidas pelos alunos.

A estrutura de cada Matriz de Referência para Avaliação de Matemática representa um recorte significativo do currículo e se apresenta no Quadro 1.

\footnotetext{
4 Meta-análise define-se como a combinação de técnicas estatísticas para resumir e combinar os resultados de estudos realizados de forma independente, voltados à mesma questão. Permite sintetizar as conclusões, podendo-se extrair uma nova conclusão.

${ }^{5}$ Por proficiência entende-se a capacidade do indivíduo em obter resultados satisfatórios, realizar algo, ter conhecimento ou domínio sobre determinada área.
} 


\section{Quadro 1- Matriz de Referência para Avaliação de Matemática}

\begin{tabular}{|c|c|c|c|}
\hline $\begin{array}{l}\text { MATEMÁTICA } \\
\downarrow \\
\qquad \underset{\text { ALUNO }}{\rightarrow}\end{array}$ & $\begin{array}{l}\text { GI } \\
\text { Competências } \\
\text { para observar - } \\
\text { esquemas } \\
\text { representativos }\end{array}$ & $\begin{array}{l}\text { GII } \\
\text { Competências } \\
\text { para realizar - } \\
\text { esquemas } \\
\text { procedimentais }\end{array}$ & $\begin{array}{lr}\text { GIII } \\
\text { Competências para } \\
\text { compreender } \\
\text { raciocínio } \\
\text { hipotético-dedutivo. }\end{array}$ \\
\hline $\begin{array}{l}\text { Desenvolver o raciocínio quantitativo e o } \\
\text { pensamento funcional, isto é, o pensamento } \\
\text { em termos de relações e a variedade de suas } \\
\text { representações, incluindo as simbólicas, as } \\
\text { algébricas, as gráficas, as tabulares e as } \\
\text { geométricas. Aplicar expressões analíticas } \\
\text { para modelar e resolver problemas. } \\
\text { (Números, operações, funções). }\end{array}$ & 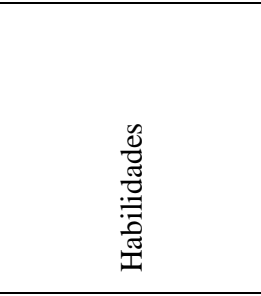 & 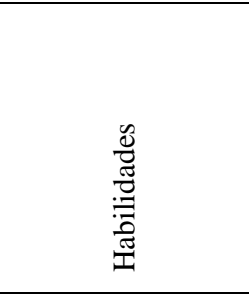 & 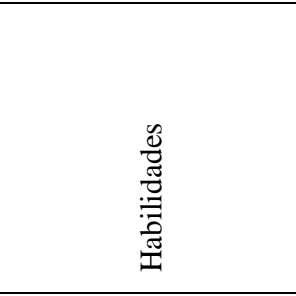 \\
\hline $\begin{array}{l}\text { Compreender as propriedades dos objetos e a } \\
\text { sua posição relativa e desenvolver o } \\
\text { raciocínio espacial por meio de construções e } \\
\text { de formas. (Espaço e Forma). }\end{array}$ & Habilidades & Habilidades & Habilidades \\
\hline $\begin{array}{l}\text { Construir e ampliar noções de variação de } \\
\text { grandeza para a compreensão da realidade e a } \\
\text { solução de problemas do cotidiano. } \\
\text { Compreender e fazer uso das medidas, ou } \\
\text { sistemas convencionais, para o cálculo de } \\
\text { perímetros, áreas, volumes e relações entre as } \\
\text { diferentes unidades de medida. (Grandezas e } \\
\text { medidas). }\end{array}$ & 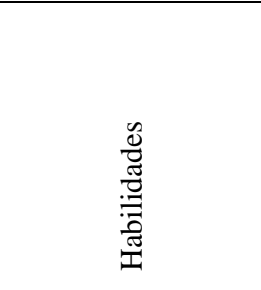 & 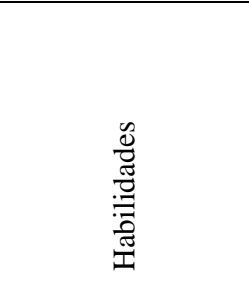 & 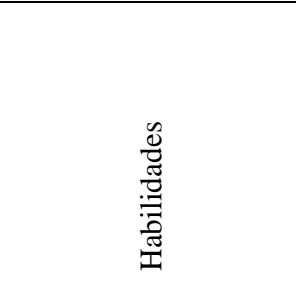 \\
\hline $\begin{array}{l}\text { Ler, construir e interpretar informações de } \\
\text { variáveis expressas em gráficos e tabelas. } \\
\text { Fazer uso das ferramentas estatísticas para } \\
\text { descrever e analisar dados, realizar } \\
\text { inferências e fazer predições. Compreender o } \\
\text { caráter aleatório e não determinístico dos } \\
\text { fenômenos naturais e sociais e utilizar os } \\
\text { conceitos e algoritmos adequados para } \\
\text { medidas e cálculos de probabilidades. } \\
\text { (Tratamento da informação). }\end{array}$ & Habilidades & Habilidades & Habilidades \\
\hline
\end{tabular}

Fonte: Brasil (2011, p.42).

Na Matriz de Referência para Avaliação, as competências ${ }^{6}$ são reunidas nos grupos GI, GII e GIII. O Grupo I é formado pelas “competências para observar”, dentre as quais estão incluídas as habilidades reconhecer, localizar, descrever, constatar e representar. No Grupo II estão as "competências para realizar", tais como classificar, ordenar, conservar, compor e decompor, fazer antecipações, calcular por estimativa, medir e interpretar. As "competências para compreender" fazem parte do Grupo III, cujas habilidades associadas são analisar, avaliar, criticar, julgar, explicar causas e efeitos, apresentar conclusões, levantar suposições, fazer prognósticos e generalizações e justificar acontecimentos.

Posteriormente à iniciativa de 1992 de desenvolver um sistema de avaliação no

\footnotetext{
${ }^{6}$ As competências cognitivas caracterizam o conjunto de ações e operações mentais utilizado pelo aluno para estabelecer relações com e entre objetos e pessoas.
} 
estado de São Paulo, intitulado Programa de Avaliação Educacional da Rede Estadual ${ }^{7}$, o SARESP passou a compor o Índice de Desenvolvimento da Educação de São Paulo (IDESP) como forma de monitorar o rendimento escolar do aluno durante sua trajetória educacional. Seria também uma fonte auxiliar de indicadores para a elaboração de planos visando à melhoria do ensino nas escolas públicas. Essa forma de avaliação foi estabelecida para atender a necessidade de ter elementos mais consistentes para apoiar uma política de avaliação eficaz por parte da Secretaria da Educação do Estado (SEE) e também por ser uma necessidade intrínseca dos sistemas educacionais. $\mathrm{O}$ desenvolvimento de políticas públicas para a educação baseado em indicadores reconhecidos era necessário para que as equipes das escolas pudessem aperfeiçoar seus projetos pedagógicos, dispondo de mais elementos para intervenções adequadas aos problemas identificados, para melhoria da aprendizagem e do desempenho dos alunos. Contudo, é fundamental observar que, de acordo com os indicativos no texto constitucional de 1988, o poder público deverá disponibilizar para a sociedade informações sobre a educação no país (Art. 206; item VII), o que posteriormente foi devidamente definido e normatizado na LDB 9394/96.

O SARESP passou a vigorar em 1996 e mesmo sendo ajustado e adequado conforme exigências e necessidades, desde então, é mantido como o Sistema de Avaliação do Rendimento Escolar do aluno no Estado de São Paulo. Começou com a participação de algumas séries do Ensino Fundamental e tinha como meta analisar o comportamento do aluno durante o ciclo, além de disponibilizar às escolas da rede pública estadual dados suficientes para que possam refletir sobre seu projeto pedagógico e processo de ensino-aprendizagem. O Instrumento era composto por questões envolvendo leitura, escrita e interpretação de textos. Em 2003, os alunos do Ensino Médio também passaram a ter suas competências e habilidades avaliadas nos mesmos quesitos. Somente em 2005 é que foram introduzidas avaliações em matemática e português realizadas pelo Sistema paulista.

Atualmente, o SARESP é aplicado no final de cada ciclo, isto é, na $4^{\mathrm{a}}$ e $8^{\mathrm{a}}$ séries do Ensino Fundamental e no $3^{\circ}$ ano do Ensino Médio. Usam dois instrumentos de avaliação: o primeiro é caracterizado pela aplicação de provas em dois dias, para analisar o desempenho dos alunos do Ensino Fundamental e Médio em questões envolvendo leitura/escrita e matemática; o segundo instrumento é o questionário

${ }^{7}$ O objetivo deste programa era aferir se havia melhoria no desempenho dos alunos que participavam do Projeto Escola-Padrão do estado de São Paulo. 
aplicado aos alunos, por meio do qual são extraídas informações sobre características pessoais, contexto socioeconômico e cultural, trajetória escolar, entre outras. Questões dessa natureza devem ser consideradas, uma vez que as desigualdades sociais têm implicações diretas sobre a educação, como apontam os estudos de Soares e Mendonça (2003), Barbosa e Fernandes (2001), Jesus e Laros (2004) e Soares e Collares (2006). Nos resultados encontrados por Soares e Mendonça (2003), por exemplo, a variável que mede a frequência do aluno a cultos religiosos exerceu efeito positivo sobre o desempenho escolar. Para o caso de Jesus e Laros (2004), ao considerarem a trajetória do aluno, afirmam que "A repetência, a evasão e o atraso escolar são fatores com altas taxas de incidência nas escolas no país, sobretudo as públicas, com reflexo direto no rendimento do aluno." (JESUS; LAROS, 2004, p.96). De acordo com Laros, Marciano e Andrade (2010), o desempenho escolar sofre, também, influência de fatores relacionados com elementos e traços que o aluno traz consigo e com o que a escola lhe oferece em termos de ensino, instalações e ambiente. Para Soares e Collares (2006), os melhores rendimentos na escola são apresentados por alunos com níveis socioeconômicos mais altos.

A utilização destes dois instrumentos de avaliação pelo SARESP tem, também, o propósito de revelar distorções no processo de seriação, além de obter indicadores educacionais com função de subsidiar a elaboração e formalização de propostas eficientes de intervenção técnico pedagógica no sistema de ensino. Enquanto o primeiro instrumento permite avaliar o desempenho e habilidades cognitivas do aluno referente às questões com problemas de português e matemática, por meio do qual é possível traçar metas para melhoria da qualidade do ensino, o segundo possibilita à SEE caracterizar o perfil dos alunos durante o processo educacional ao qual estão submetidos, possibilitando a identificação de interferências provenientes desses fatores no processo ensino-aprendizagem.

Em linhas gerais, os resultados mostrados pelos Relatórios Pedagógicos do SARESP têm sido insatisfatórios. O resultado do SARESP de 2007 mostrou que o desempenho na prova de matemática de aproximadamente $71 \%$ dos alunos da $3^{\mathrm{a}}$ série do Ensino Médio ficou abaixo do nível básico, apenas 3,7\% dos alunos permaneceram no nível adequado e menos de $1 \%$ apresentou proficiência avançada em matemática (TORINO; MENDES, 2009). Em 2009, a porcentagem de alunos com proficiência em matemática abaixo do básico caiu para $58,3 \%$, somente $4,4 \%$ estiveram no nível 
adequado e apenas $0,5 \%$ teve a proficiência em matemática classificada no nível avançado $^{8}$.

Embora tenha ocorrido uma leve queda no percentual de alunos abaixo do nível básico, no que se refere à proficiência em matemática, conforme medido pelo SARESP em 2007 e 2009, as quais foram respectivamente $71 \%$ e 58,3\%, os resultados permanecem fora do padrão de desempenho e de domínio cognitivo aceitável no equivalente qualitativo descrito para esse nível de ensino. Ao constatar que, tanto em 2007 quanto em 2009, menos de 1\% dos alunos concluintes da $3^{\text {a }}$ série do Ensino Médio tiveram a proficiência em matemática enquadrada no nível avançado, os resultados do SARESP 2010 foram analisados com foco na proficiência em matemática dos alunos da $3^{a}$ série do Ensino Médio, buscando verificar o desempenho nesse momento. Esses dados possibilitam uma visão de trajetória e tendência, a partir de um estudo mais refinado dos resultados, que permite intervenções pontuais com vistas a uma melhoria do aprendizado e, com efeito, do desempenho resultante.

\section{Meta-Análise dos Resultados Atuais do SARESP}

Realizado pela Secretaria da Educação do Estado de São Paulo, o SARESP avalia milhões de alunos das escolas do estado de São Paulo buscando investigar, comparar e acompanhar o desenvolvimento da escolaridade básica na rede pública de ensino paulista. Tal avaliação externa visa também disponibilizar informações referentes à situação da educação nesse nível de ensino de forma a orientar os gestores na complexa, mas necessária, tarefa de monitorar políticas voltadas para a melhoria na qualidade no ensino. Neste contexto, no presente estudo, foram analisados os resultados obtidos pelos alunos da $3^{\text {a }}$ série do Ensino Médio das escolas públicas do estado de São Paulo na prova de matemática, nas últimas edições do SARESP.

O Quadro 2 contém informações referentes aos níveis de proficiência, intervalos de pontuação, classificação e descrição, utilizados pelo SARESP. A primeira coluna do Quadro 2 mostra que os níveis de proficiência se dividem em quatro categorias: Abaixo do Básico, Básico, Adequado e Avançado. Cada um dos níveis de proficiência possui um intervalo de pontuação, definido a partir da Teoria de Resposta ao Item, mostrado na segunda coluna. Os níveis de proficiência, combinados com seus intervalos de pontuação, são classificados em um de três grupos, mostrados na terceira coluna, a saber, Insuficiente, Suficiente e Avançado.

${ }^{8}$ Brasil (2011). 
Quadro 2 - Classificação e descrição dos níveis de proficiência em matemática do SARESP

\begin{tabular}{|c|c|c|c|}
\hline $\begin{array}{c}\text { Níveis de } \\
\text { Proficiência }\end{array}$ & $\begin{array}{l}\text { Intervalos de } \\
\text { Pontuação }\end{array}$ & Classificação & Descrição \\
\hline $\begin{array}{l}\text { Abaixo do } \\
\text { básico }\end{array}$ & Menor que 275 & Insuficiente & $\begin{array}{l}\text { Os alunos demonstram domínio insuficiente dos } \\
\text { conteúdos, competências e habilidades desejáveis } \\
\text { para o ano/série em que se encontram. }\end{array}$ \\
\hline Básico & $\begin{array}{l}\text { Igual ou acima } \\
\text { de } 275 \text { e abaixo } \\
\text { de } 350\end{array}$ & & $\begin{array}{l}\text { Os alunos demonstram domínio mínimo dos } \\
\text { conteúdos, competências e habilidades, mas } \\
\text { possuem estruturas necessárias para interagir com a } \\
\text { proposta curricular no ano/série subsequente. }\end{array}$ \\
\hline Adequado & $\begin{array}{l}\text { Igual ou acima } \\
\text { de } 350 \text { e abaixo } \\
\text { de } 400\end{array}$ & & $\begin{array}{l}\text { Os alunos demonstram domínio pleno do } \\
\text { conteúdo, competências e habilidades desejáveis } \\
\text { para o ano/série em que se encontram. }\end{array}$ \\
\hline Avançado & $\begin{array}{c}\text { Igual ou acima } \\
\text { de } 400\end{array}$ & Avançado & $\begin{array}{l}\text { Os alunos demonstram conhecimentos e domínio } \\
\text { dos conteúdos, competências e habilidades acima } \\
\text { do requerido no ano/série em que se encontram. }\end{array}$ \\
\hline
\end{tabular}

Fonte: Brasil (2012).

Deve-se observar que os níveis de proficiência Básico e Adequado são classificados como Suficientes. A quarta coluna contém uma breve descrição de cada nível de proficiência. Conforme a pontuação obtida na prova de matemática, o aluno é classificado em um dos níveis de proficiência, isto é, Insuficiente, Adequado ou Avançado. Vale ressaltar que o padrão de desempenho esperado pelo SARESP é o nível Adequado.

O comportamento da proficiência em matemática dos alunos da $3^{\mathrm{a}}$ série do Ensino Médio9 ${ }^{9}$ medido pelo SARESP no período entre 2007 e 2013, é mostrado no Gráfico 1.

\footnotetext{
${ }^{9}$ De acordo com o Sumário Executivo SARESP 2007 e de forma especulativa, por não ser objeto deste estudo, considera-se que os valores correspondentes aos níveis Abaixo do Básico e Básico em 2007 ficam distantes dos demais anos devido, fundamentalmente, à Matriz de Referência do SARESP não estar calibrada adequadamente às questões da prova. Além disso, mudanças na forma de aplicação da prova com a utilização de avaliadores externos modifica o ambiente e coloca variáveis concorrentes com a atenção dos avaliados, contudo sem grandes alterações no conjunto do sistema (BRASIL, 2007).
} 
Gráfico 1: Evolução temporal dos níveis de proficiência em matemática na $3^{\text {a }}$ série do Ensino Médio

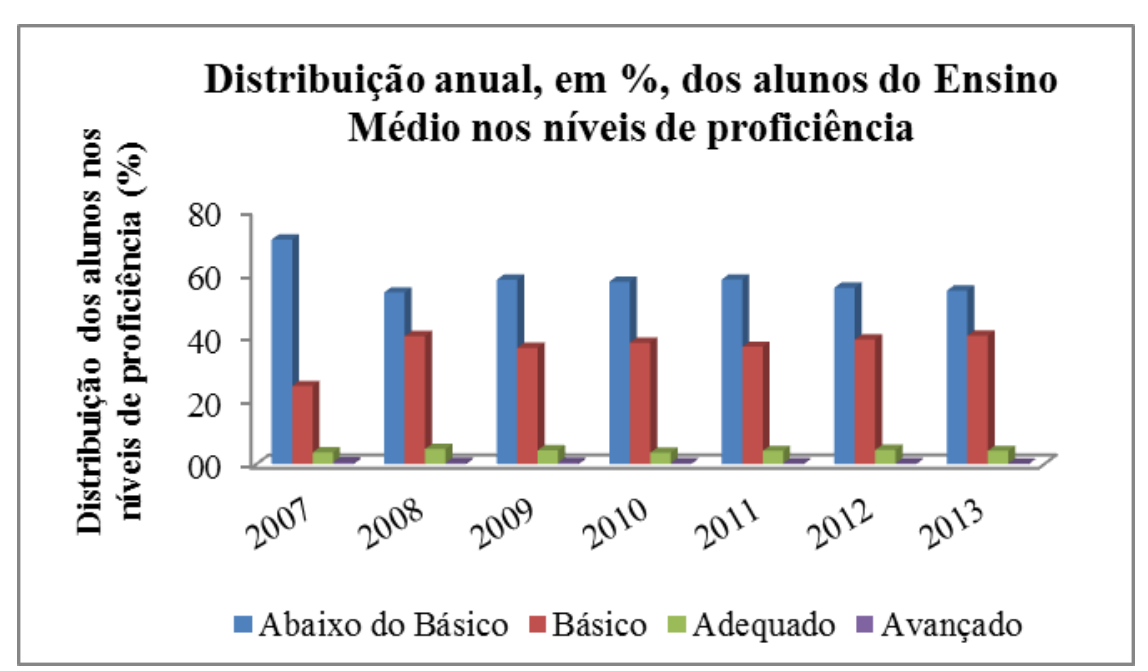

Fonte: Elaboração própria.

O Gráfico 1 mostra que, durante os sete anos considerados, os níveis Adequado e Avançado não sofreram alterações significativas, permaneceram extremamente baixos, sendo alarmantes os valores referentes ao nível Avançado, os quais não atingiram nem mesmo 1\%. Enquanto a porcentagem de alunos no nível Avançado permaneceu a mesma nos anos de 2010 e 2011, houve um aumento na porcentagem de alunos com proficiências classificadas no nível Adequado, visto que de 3,6\% em 2010, tal porcentagem passou para 4,2\% em 2011. Essa situação, no período analisado, parece apontar a capacidade de melhorar os conhecimentos básicos de matemática, dentro de um determinado espectro de conhecimento, mas de não ir muito além dele.

Já as distribuições dos alunos nos níveis de proficiência Abaixo do Básico e Básico oscilaram substancialmente entre os anos de 2007 e 2008. Enquanto em 2007, $71 \%$ dos alunos estiveram no nível Abaixo do Básico, em 2008 este valor sofreu uma redução, igualando-se a aproximadamente 54\%. Esta redução de $17 \%$ sugere melhora na qualidade do ensino de matemática aos alunos concluintes do Ensino Médio.

Para o nível Básico, a distribuição dos alunos também ocorreu de forma positiva. Enquanto em 2007 apenas 24,7\% alcançaram este nível, em 2008 este valor foi quase o dobro, igual a 40,5\%, evidenciando maior rendimento dos alunos da $3^{\mathrm{a}}$ série do Ensino Médio em matemática. Para os anos de 2009 e 2010, os valores observados apresentaram mínimas diferenças entre si, conforme mostra a Tabela 1.

A Tabela 1 mostra ainda que, em 2013 o percentual de alunos classificados no nível Básico foi o mais alto no período considerado, igual a 40,6\%, percentual que 
reflete as quedas observadas nos níveis Abaixo do Básico e Adequado. Enquanto o percentual de alunos no nível atingiu 54,9\%, segundo mais baixo do período analisado, somente 4,2\% dos alunos da $3^{\mathrm{a}}$ série do Ensino Média atingiram o nível Avançado de proficiência em matemática.

Tabela 1 - Distribuição, em \%, dos alunos nos níveis de proficiência entre 2007 e 2013

\begin{tabular}{cccccccc}
\hline Níveis & $\mathbf{2 0 0 7}$ & $\mathbf{2 0 0 8}$ & $\mathbf{2 0 0 9}$ & $\mathbf{2 0 1 0}$ & $\mathbf{2 0 1 1}$ & $\mathbf{2 0 1 2}$ & $\mathbf{2 0 1 3}$ \\
\hline Abaixo do Básico & 71,0 & 54,3 & 58,3 & 57,7 & 58,4 & 55,8 & 54,9 \\
Básico & 24,7 & 40,5 & 36,8 & 38,4 & 37,1 & 39,4 & 40,6 \\
Adequado & 3,7 & 4,8 & 4,4 & 3,6 & 4,2 & 4,5 & 4,2 \\
Avançado & 0,6 & 0,4 & 0,5 & 0,3 & 0,3 & 0,3 & 0,2 \\
\hline
\end{tabular}

Fonte: Baseado em Brasil (2010, 2011) e Torino e Mendes (2009).

O Gráfico 2 mostra o comportamento temporal da proficiência em matemática aferida e adequada dos alunos da $3^{\text {a }}$ série do Ensino Médio, evidenciando a distância entre ambas.

A proficiência Adequada é considerada para a pontuação mínima de 350 pontos. A distância entre as proficiências aferida e adequada é surpreendente. Enquanto para os anos de 2007, 2009, 2010, 2011, 2012 e 2013 as proficiências aferidas foram 263,7, 269,4, 269,2 269,7, 2170,4 e 268,7, respectivamente, permanecendo substancialmente distantes da média adequada, em 2008, cujo valor da proficiência aferida foi 273,8, a nota alcançada teve a menor distância entre os índices e, ainda assim, observa-se uma discrepância preocupante. 
Gráfico 2. Comportamento temporal das proficiências aferida e adequada em matemática na $3^{a}$ série do Ensino Médio

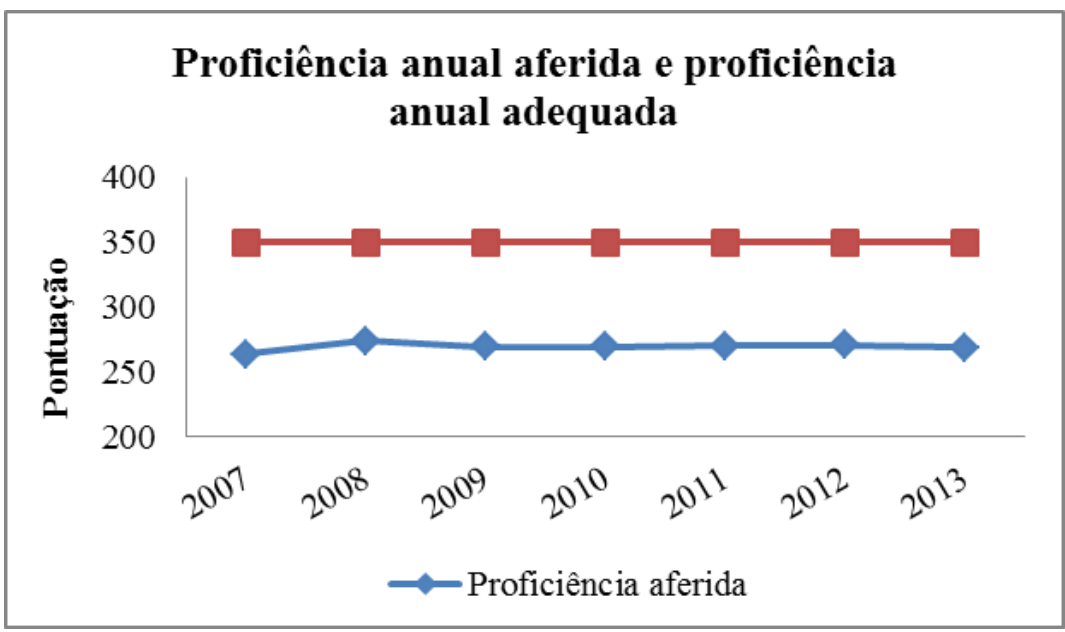

Fonte: Elaboração própria.

No presente estudo, a partir da meta-análise dos resultados atuais do SARESP, buscou-se realizar uma projeção para a distribuição dos alunos em níveis de proficiências para o período compreendido entre 2014 e 2016.

Como método para a projeção, foi considerado um intervalo de confiança para a média, com nível de significância $\alpha=10 \%$, assumindo uma amostra de tamanho igual a cinco, já que as informações disponíveis são referentes a cinco anos, de 2007 a 2011, conforme mostrado na Tabela 1. Inicialmente, foram calculadas a média e o desvio padrão para cada um dos níveis, respectivamente, por meio das expressões:

$$
\bar{X}=\frac{\sum_{i=1}^{n} X_{i}}{n},
$$

onde $\bar{X}$ é a média amostral, $X_{i}$ representa cada um dos valores observados para os níveis Abaixo do Básico, Básico, Adequado e Avançado, entre os anos de 2007 e 2012, $n$ indica o tamanho amostral, e

$$
S=\sqrt{\frac{\sum_{i=1}^{5}\left(X_{i}-\bar{X}\right)^{2}}{n-1}},
$$


sendo $S$ o desvio padrão amostral e $\bar{X}, X_{i}$ e $n$ definidos como anteriormente. Em seguida, as margens de erro ${ }^{10}$ foram obtidas utilizando:

$$
\text { Margem de erro }=1,64 \cdot \frac{S}{\sqrt{n}} .
$$

Conhecidas as margens de erros, os limites inferiores e superiores dos intervalos de confiança para a média foram calculados por:

$$
I C_{\bar{X}}=\left(\bar{X}-1,64 \cdot \frac{S}{\sqrt{n}} ; \bar{X}+1,64 \cdot \frac{S}{\sqrt{n}}\right)
$$

$\mathrm{Na}$ Tabela 2 são apresentadas as projeções para as distribuições dos alunos nos níveis de proficiência para o período de 2014 a 2016. Comparando as projeções para a distribuição de alunos da $3^{\text {a }}$ série do Ensino Médio nos níveis de proficiência entre 2014 e 2015, é possível observar uma melhora, pois enquanto a porcentagem de alunos Abaixo do Básico cai de 58,63\% para 57,22\%, mostrando uma quantidade menor de alunos no nível mais baixo, ocorre um aumento nas porcentagens de alunos classificados no nível Básico, de 36,79\% para 38,23\%.

As projeções para a distribuição dos alunos pertencentes ao nível do Básico mostram que em 2014 tal quantidade tende a cair quase 4,0\%, passando de 40,6\% em 2013 para 36,8\% em 2014, e estabiliza-se em torno de 38\% para o período restante, considerado na projeção. Essa queda observada por meio da projeção entre 2013 e 2014 reflete um aumento de 3,7\% no percentual de alunos classificado no mais baixo dos níveis de proficiência. Enquanto em 2013 aproximadamente 55,0\% dos alunos avaliados estiveram Abaixo do Básico, para 2014 estima-se que tal quantidade seja próxima de 59,0\%. Para os níveis Adequado e Avançado, as projeções mostram percentuais semelhantes entre 2014 e 2016, permanecendo, em média, próximos de $4,2 \%$ e $0,33 \%$, respectivamente.

${ }^{10} \mathrm{Na}$ expressão (2.4), o valor 1,64 corresponde ao nível de significancia $\alpha=10 \%$. 
Tabela 2 - Projeção da distribuição de alunos nos níveis de proficiência entre 2014 e 2016

\begin{tabular}{|c|c|c|c|c|}
\hline \multirow{2}{*}{ Anos } & \multirow{2}{*}{ Níveis } & \multirow{2}{*}{ Projeções (\%) } & \multicolumn{2}{|c|}{ Intervalos de Confiança } \\
\hline & & & Limite Inferior & Limite Superior \\
\hline \multirow{4}{*}{2014} & Abaixo do Básico & 58,63 & 55,73 & 57,99 \\
\hline & Básico & 36,79 & 37,47 & 39,56 \\
\hline & Adequado & 4,20 & 4,04 & 4,50 \\
\hline & Avançado & 0,37 & 0,28 & 0,40 \\
\hline \multirow{4}{*}{2015} & Abaixo do Básico & 57,22 & 56,34 & 58,11 \\
\hline & Básico & 38,23 & 37,33 & 39,13 \\
\hline & Adequado & 4,20 & 4,02 & 4,37 \\
\hline & Avançado & 0,33 & 0,28 & 0,39 \\
\hline \multirow{4}{*}{2016} & Abaixo do Básico & 57,04 & 56,13 & 57,96 \\
\hline & Básico & 38,47 & 37,59 & 39,35 \\
\hline & Adequado & 4,16 & 3,98 & 4,35 \\
\hline & Avançado & 0,31 & 0,27 & 0,35 \\
\hline
\end{tabular}

Fonte: Elaboração própria.

O Gráfico 3 mostra o comportamento das projeções para cada nível de proficiência, considerado pelo SARESP, para os anos de 2014 a 2016. 
Gráfico 3 - Comportamento temporal das projeções para as distribuições de alunos nos níveis de proficiências em matemática na $3^{\mathrm{a}}$ série do Ensino Médio, entre 2014 e 2016

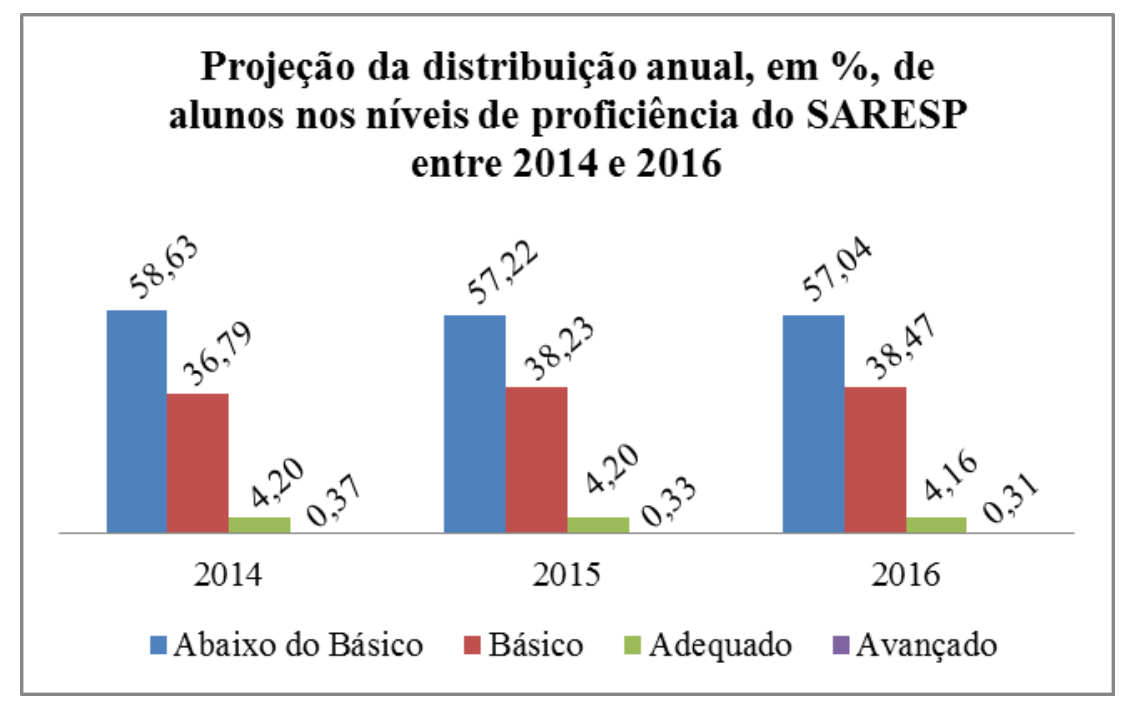

Fonte: Elaboração própria.

Na Tabela 3 são apresentados os valores observados o período de 2007 a 2013 e as projeções realizadas para os anos de 2014 a 2016.

Tabela 3 - Percentual de alunos nos níveis de proficiência entre 2007 e 2014

\begin{tabular}{lccccccccccc}
\hline Níveis & $\mathbf{2 0 0 7}$ & $\mathbf{2 0 0 8}$ & $\mathbf{2 0 0 9}$ & $\mathbf{2 0 1 0}$ & $\mathbf{2 0 1 1}$ & $\mathbf{2 0 1 2}$ & $\mathbf{2 0 1 3}$ & $\mathbf{2 0 1 4}$ & $\mathbf{2 0 1 5}$ & $\mathbf{2 0 1 6}$ \\
\hline Abaixo do Básico & 71,0 & 54,3 & 58,3 & 57,7 & 58,4 & 59,9 & 57,7 & 58,63 & 57,22 & 57,04 \\
Básico & 24,7 & 40,5 & 36,8 & 38,4 & 37,1 & 35,5 & 37,7 & 37,79 & 38,23 & 38,47 \\
Adequado & 3,7 & 4,8 & 4,4 & 3,6 & 4,2 & 4,14 & 4,2 & 4,2 & 4,20 & 4,16 \\
Avançado & 0,6 & 0,4 & 0,5 & 0,3 & 0,3 & 0,4 & 0,38 & 0,37 & 0,33 & 0,31 \\
\hline
\end{tabular}

Fonte: Elaboração própria.

Observa-se que entre 2007 e 2008 as diferenças entre os valores observados para as distribuições de alunos entre os quatro níveis de proficiência considerados foram 
maiores. Considerando o nível Abaixo do Básico, é possível observar a ocorrência de uma queda significativa no percentual de alunos que demonstram domínio insuficiente dos conteúdos, competências e habilidades desejáveis para o ano/série em que se encontram, já que tal percentual passou de 71\% em 2007 para 54,3\% em 2008.

Esta diferença explica o aumento do percentual de alunos observado no nível Básico no mesmo período ao passar de $24,7 \%$ para $40,5 \%$. Tal resultado implica em um aumento na quantidade de alunos da terceira série do Ensino Médio que demonstram domínio mínimo dos conteúdos, competências e habilidades, mas possuem estruturas necessárias para interagir com a proposta curricular no ano/série subsequente.

Ainda na categoria Abaixo do Básico destaca-se também a queda no percentual de alunos ocorrida entre os anos de 2012 e 2013. Enquanto em 2012 quase $60 \%$ dos alunos classificaram-se no pior dos níveis de proficiência em matemática, em 2013 esse percentual foi de 57,7, evidenciando uma redução de 3,6\% na quantidade de alunos no nível Abaixo do Básico. Esta queda reflete um aumento no percentual de alunos da rede estadual de ensino que alcançaram nota correspondente ao nível de proficiência Básico na prova de matemática, uma vez que o percentual de alunos passou de 35,5\% em 2012 para quase $38 \%$ em 2013, evidenciando um aumento de aproximadamente $6 \%$.

A Tabela 3 mostra que, para o nível Adequado, o qual inclui alunos que demonstram domínio pleno do conteúdo, competências e habilidades desejáveis para o ano/série em que se encontram, o percentual de alunos oscilou significativamente entre 2007 e 2011. O maior aumento, igual a 30\%, foi observado entre 2007 e 2008, período em que o percentual de alunos nessa categoria passou de 3,7\% para 4,8\%. Em 2009 e 2010, reduções na quantidade de alunos no nível Adequado foram observadas, uma vez que o percentual passou de 4,8\% para 4,4\% em 2009 e atingiu somente 3,6\% em 2010, isto é, quase $20 \%$. A partir de 2010, o percentual de alunos nesse nível de proficiência manteve-se estável até 2013 , em torno de 4,2\% e, conforme a projeção realizada, assim deverá ficar até 2016.

Em relação ao nível de proficiência Avançado em matemática, não é possível fazer as mesmas afirmações, já que, embora tenha exibido o maior valor em 2007, os valores observados e projetados se mantiveram quase que constantes para os demais anos. Em média, somente $3 \%$ ou $4 \%$ dos alunos são capazes de demonstrar conhecimentos e domínio dos conteúdos, competências e habilidades acima do requerido no ano/série em que se encontram. 
O Gráfico 4 mostra o comportamento dos valores observados entre 2007 e 2013 e as projeções para o período de 2014 a 2016, para as porcentagens de alunos classificados em cada um dos níveis considerados pelo SARESP.

Gráfico 4 - Comportamento temporal dos valores observados e das projeções para as distribuições de alunos nos níveis de proficiências em matemática na $3^{\mathrm{a}}$ série do Ensino Médio, entre 2007 e 2016

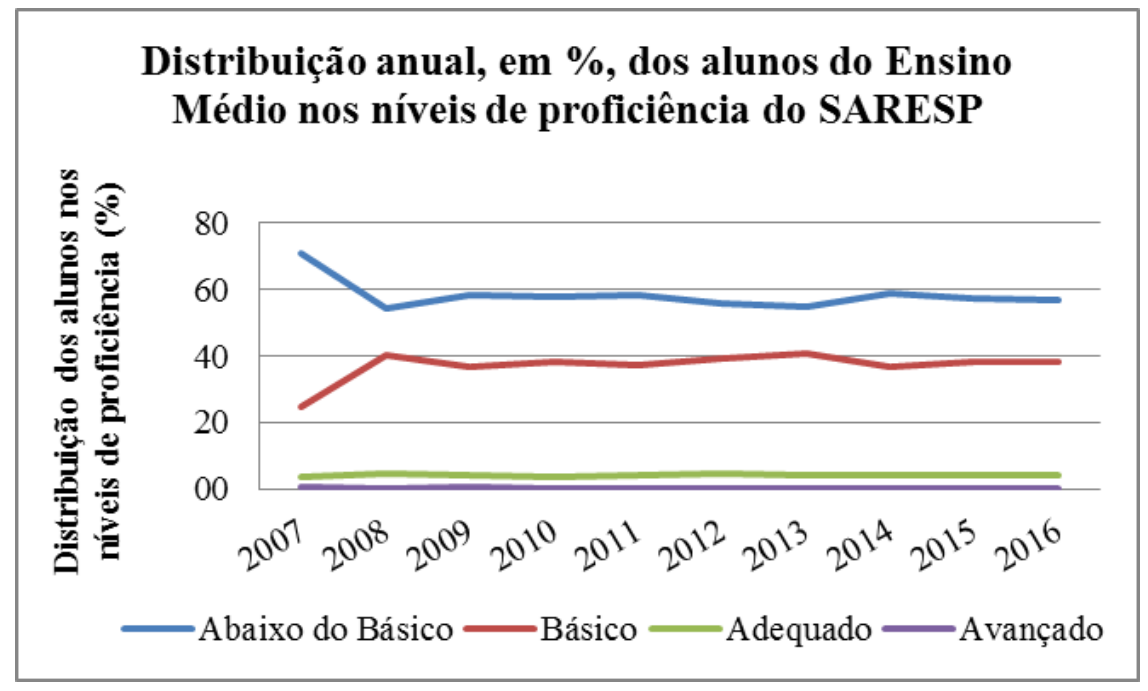

Fonte: Elaboração própria.

Além dos Relatórios Pedagógicos 2010 e 2011 SARESP, foi analisado também o Relatório dos Estudos do SARESP 2010, no qual são apresentados resultados das análises das informações coletadas pelos questionários de contexto aplicados para caracterizar o perfil de gestores, docentes, alunos e pais. Há certo esforço em conhecer o contexto de origem dos alunos, considerando a pertinência do meio em que vivem para analisá-los.

Dentre as diversas informações disponibilizadas, o Relatório dos Estudos do SARESP 2010 mostra que, para aproximadamente 60\% dos alunos, o professor de matemática incentiva-os a melhorar o desempenho, é atencioso e auxilia os alunos a realizar suas tarefas, e explica a matéria até que todos entendam. Adicionalmente, $50 \%$ oferecem aos alunos a oportunidade de expressar suas opiniões e propõe atividades de resolução de problemas variados e apenas 33\% dos professores relacionam os conteúdos de matemática às situações cotidianas. Em algumas aulas, 47\% dos professores propõem aos seus alunos trabalhos a serem realizados em grupos e $42 \%$ costumam 
mostrar aplicação dos conteúdos estudados na matemática em outras disciplinas. Nesse Relatório há também informações preocupantes, tais como a que se refere ao tempo que o aluno passa por dia fazendo as lições. Aproximadamente $32 \%$ dos alunos passa entre 20 e 40 minutos fazendo lições. Somente $13,6 \%$ dos alunos destinam mais de uma hora à "lição de casa" e 10,6\% dizem não fazer "lição de casa".

A análise desse Relatório Pedagógico e do Relatório dos Estudos, gerados a partir da aplicação do SARESP, permite que se identifique possíveis caminhos para solucionar essa problemática dos baixos índices de rendimento escolar evidenciados pelos alunos.

\section{Conclusão}

O presente estudo teve como objetivo buscar e apresentar, por meio da metaanálise, uma discussão que mostrasse o estado e a tendência da situação dos desempenhos observados nos resultados do SARESP entre 2007 e 2013, dos alunos da $3^{a}$ série do Ensino Médio nas escolas da rede pública estadual na matemática. Tais resultados foram meta analisados, utilizando-se dados, gráficos e tabelas construídos para esse fim.

Foi evidenciada a lacuna existente entre a proficiência em matemática aferida e a adequada, mostrada pelos alunos no $3^{\circ}$ ano do Ensino Médio. Nos cálculos de projeção no tempo, constatou-se a tendência pela permanência desses índices, o que indica a necessidade de revisão e/ou melhorias nos padrões metodológicos de ensino, nas condições de trabalho docente, na dinâmica da cultura escolar, nos focos de investimentos e de gestão nesse momento do processo escolar. Persistindo esse comportamento no desempenho do sistema pode-se considerar que os objetivos estabelecidos no atual Plano Nacional de Educação - 2011/2020 - pelo menos nesse contexto analisado, já se encontram comprometidos. Nesse sentido, é preciso que sejam revistas as atuais políticas públicas para o ensino médio dentro do contexto educacional, buscando melhorias na qualidade desse momento da escolarização pública.

Embora não se possa negar que esforços têm sido feitos nos últimos 20 anos com vistas à melhoria, há que se perguntar: estarão tais esforços sendo dirigidos, de fato, onde há necessidade da intervenção? Por que se mantém, de forma persistente, os padrões de desempenho observados desde 2007? O período analisado parece apontar a capacidade de melhorar os conhecimentos básicos em matemática dos alunos dentro de um determinado espectro de conhecimento, mas de não ir além dele. Por quê? Além do 
mais, é preciso que as deficiências do sistema escolar, envolvendo alunos, pais, ambiente escolar, gestores e todos os que, de forma direta ou indireta, participam do processo ensino-aprendizagem, sejam identificadas e superadas.

Ainda há uma evidente necessidade de que sejam desenvolvidos estudos correlativos que possa estabelecer com clareza, por exemplo, a relação existente entre os resultados insuficientes de nossos alunos ao sair do Ensino Médio e as condições de trabalho do professor. Pode-se dizer também o mesmo em relação ao momento da vida desses alunos - em plena adolescência - e condições socioeconômica que têm. Como, e em que grau, a complexidade da diversidade na sala de aula da escola democrática interfere ou pode interferir no aprendizado e, com efeito, no desempenho dos educandos? A aprendizagem, enquanto fenômeno complexo que é, exige um grau significativamente maior de estudos e pesquisas para oferecer respostas confiáveis e, se possível, oferecer caminhos para superação dos problemas aqui levantados. Contudo, para isso, há que se aprofundarem os estudos que aqui se desenvolve.

Estudos quantitativos de maior complexidade não têm sido desenvolvidos de forma satisfatória, ou mesmo suficiente, no Brasil, pela falta de uma base de dados composta e organizada a partir de metodologias confiáveis para evitar interpretações inadequadas dos resultados observados. Para isso é necessário a sistematização e a frequência na coleta dados. Como esses procedimentos somente foram instituídos, no conjunto do contexto educacional brasileiro, há muito pouco tempo, ainda há ajustes e complementações a serem feitas. Por isso, é preciso que a avaliação seja aprimorada, rompa com a concepção de valoração de resultados e assuma o papel de instrumento regulador - na dimensão pedagógica - no processo educativo escolar.

Sendo a avaliação de sistemas e desempenho uma atividade com implicações sociais e econômicas por envolver, não só aspectos técnicos e/ou metodológicos, mas também aspectos psicológicos, políticos, éticos e sociológicos, podem-se dela extrair alternativas que proporcionem melhor entendimento sobre o desenvolvimento e desempenho do processo e as possíveis melhorias no ensino.

Este trabalho caracteriza-se como ponto de partida para uma investigação mais ampla e acurada sobre aspectos que envolvem a educação brasileira, as condições sob as quais se desenvolvem o possível apoio ao trabalho docente e de gestão e o uso de técnicas estatísticas desenvolvidas e aprimoradas para esse fim. 


\section{A DISCUSSION META-ANALYTICAL PERFORMANCE IN MATHEMATICS FOR SECONDARY EDUCATION BASED ON THE RESULTS \\ OF CURRENT SARESP}

ABSTRACT: The objective of this work is to perform a meta-analysis of the current results of SARESP, considering the math proficiency of students in 3rd year high school of public schools. This meta-analysis revealed mismatches in the educational system as a whole in the various involved segments, directly or indirectly, which contribute to the teaching-learning process of the individual. Comparing the current results of SARESP was possible to observe the great deficiency presented by the students of 3rd year high school in solving mathematical problems involving simple concepts, sorting them at levels below the adequate when compared with the expected performance level to the series that they are. Based on this fact, which is unacceptable, we concluded that there is an immediate need to seek for explanation and overcoming ways for this situation. Otherwise, Brazilian education level will remain below of the basic.

KEYWORDS: SARESP. High school. Math proficiency. Meta-analysis.

\section{REFERÊNCIAS}

ANDRADE, D. F.; KLEIN, R. Métodos estatísticos para avaliação educacional: teoria da resposta ao item. Boletim da ABE, São Paulo, v.15, n.43, p.21-28, 1999.

ANDRADE, D. F.; TAVARES, H. R.; VALLE, R. C. Teoria de resposta ao item: conceitos e aplicações. São Paulo: Associação Brasileira de Estatística, 2000

BARBOSA, M. E. F.; FERNANDES, C. A escola brasileira faz diferença? uma investigação dos efeitos da escola na proficiência em matemática dos alunos da $4^{\mathrm{a}}$ série. In: FRANCO, C. Avaliação, ciclos e promoção na educação. Porto Alegre: ARTMED, 2001. p.121-153.

BARBOSA, M. E. F.; FERNANDES, C. Modelo multinível: uma aplicação a dados de avaliação educacional. Estudos em Avaliação Educacional, São Paulo, n.22, p.135$153,2000$.

BIZELLI, J. L. Inovação: limites e possibilidades para aprender na Era do Conhecimento. São Paulo: Ed. da UNESP: Cultura Acadêmica, 2013.

BRASIL. Secretaria da Educação do Estado de São Paulo. Fundação para o Desenvolvimento da Educação - FRD. Relatório Pedagógico SARESP Matemática 2012. São Paulo, 2012. 
Relatório Pedagógico SARESP Matemática 2011. São Paulo, 2011.

Relatório Pedagógico SARESP Matemática 2010. São Paulo, 2010.

Sumário Executivo SARESP 2007. São Paulo, 2007.

JESUS, G. R.; LAROS, J. A. Eficácia escolar: regressão multinível com dados de avaliação em larga escala. Avaliação Psicológica, Porto Alegre, v.3, n.2, p.93-106, 2004.

LAROS, J. A.; MARCIANO, J. L. P.; ANDRADE, J. M. Fatores que afetam o desempenho na prova de matemática do SAEB: um estudo multinível. Avaliação Psicológica, Porto Alegre, v.9, n.2, p.173-186, 2010.

LEMES, S. S. A avaliação educacional e escolar revisitada e a reflexão pontual de conceitos, fundamentos e indicadores frente às demandas para a escolarização atual. In: RIBEIRO, R.; LEMES, S. S.; MONTEIRO, S. I. Avaliação e gestão escolar: reflexos e pesquisas educacionais. São Carlos: RIMA, 2010. p.65-78.

SOARES, J. F.; COLLARES, A. C. M. Recursos familiares e o desempenho cognitivo dos alunos do ensino básico brasileiro. Dados: Revista de Ciências Sociais, Rio de Janeiro, v.49, n.3, p.615-650, 2006.

SOARES, T. M.; MENDONÇA, M. C. M. Construção de um modelo de regressão hierárquico para dados do SIMAVE-2000. Pesquisa Operacional, Rio de Janeiro, v.23, n.3, p.421-441, 2003.

TORINO, C.; MENDES, C. R. Avaliação educacional e educação estatística - um olhar sobre os resultados do SARESP. In: ENCONTRO DE INICIAÇÃO CIENTÍFICA DA PUC-CAMPINAS, 14., 2009, Campinas. Anais... Campinas: PUC, 2009. Disponível em: < https://www.puccampinas.edu.br/websist/portal/pesquisa/ic/pic2009/resumos/2009825_01123_2073591 43_res7AB.pdf>. Acesso em: 11 jun. 2014. 